\title{
Optimization of Biomass of Keratinase Producing Bacillus sp CBNRBT2 to Utilize in Whole Cell Immobilization for Feather Degradation
}

\author{
Dhiva S ${ }^{1}$, Sreelakshmi $\mathbf{R}^{1}$, Sruthi $S^{1}$, Biji $\mathbf{U}^{1}$, Narendrakumar $\mathbf{G}^{2}$, Jane Cypriyana P J ${ }^{2}$, Raji $\mathbf{P}^{2}$, Antony \\ V Samrot ${ }^{3, *}$ (D) \\ 1 Department of Microbiology, Sree Narayana College, Alathur, Palakkad, Kerala - 678682 \\ 2 Department of Biotechnology, School of Bio and Chemical Engineering, Sathyabama Institute of Science and Technology, \\ Sholinganallur, Rajiv Gandhi Salai, Chennai, Tamil Nadu, 600 119, India \\ 3 Department of Biomedical Sciences, Faculty of Medicine and Biomedical Sciences, MAHSA University, Jalan SP2, \\ Bandar Saujana Putra, 42610, Jenjarom, Selangor, Malaysia \\ * Correspondence: antonysamrot@gmail.com;
}

Received: 16.06.2020; Revised: 2.07.2020; Accepted: 4.07.2020; Published: 7.07.2020

\begin{abstract}
Bacillus sp CBNRBT2, obtained from Centre for Bioscience and Nanoscience Research, was used in this study. Initially, biomass was optimized for the incubation period, $\mathrm{pH}$, and temperature, following biomass optimization with RSM. The obtained organism was able to produce keratinase, which was found to be a $64 \mathrm{KDa}$ protein. Now the biomass produced using the optimized condition was immobilized and checked for its ability to degrade keratinase. Efficiency was compared with the whole organism. Immobilized organisms were degrading keratin and feather better. It was found to reduce featherweight by $41 \%$. Thus, this immobilized bacterium can be used for poultry waste treatment.
\end{abstract}

Keywords: Bacillus sp.; keratinase; whole-cell immobilization; feather degradation.

(C) 2020 by the authors. This article is an open-access article distributed under the terms and conditions of the Creative Commons Attribution (CC BY) license (https://creativecommons.org/licenses/by/4.0/).

\section{Introduction}

A bulk quantity of feathers is produced as a byproduct from processing more than 400 million chickens by the poultry industry globally [1]. Due to poor management, there was an increase in the accumulation of feathers which has reached 5 million tons [2], and it has been dumped as waste material, which leads to global environmental pollution such as air, land pollution, nearby water bodies, etc. Feathers are containing blood act as a source for a host for pathogens, including Vibrio and Salmonella. They add chemical pollutants like hydrogen sulfide, ammonia etc. and these conditions obviously invites health issues to the human population [3]. Sometimes, high-class mattresses contain these feathers. These feathers are even used for making ornaments, coats, etc. [4]. The alternative uses of feather waste are very necessary to prevent feather pollution. Much research has been carried out to find a suitable solution for feather waste management, and finally, it was identified that feather waste could be converted into fertilizer, biodegradable plastic, biofuel, fuel storage, electrical device, and feather meal due to its high protein content.

Feathers of chicken are hosting $90 \%$ keratin [5], and the complex structure limits its degradation too. There are a few methods of degradation, including chemical, mechanical, and biological methods [6]. Other than biological methods, both the other methods lead to the 
destruction of amino acids, such as methionine, lysine, and tryptophan [7]. Thus the obtained protein will not be having good quality and digestibility [8]. These methods are considered to be a major drawback of degradation. Researchers identified that there are diverse groups of microorganisms like fungi, actinomycetes, and several bacterial species such as Bacillus sp., Pseudomonas sp. that produce keratinase [9], which can degrade the keratin better with recyclable products. These keratinases are used in food and feed supplements [10], with high nutritive value. Thus, the enzymes acquired its market value like other proteases [11]. The economically useful keratin degraded products are nitrogenous fertilizers, biodegradable films, glues, and foils. Various studies revealed that the biological method of keratin waste degradation is much safer than other commercial methods, and it is accepted as environment friendly. Whereas, immobilized cells have more productivity when compared to crude or purified microbial enzymes for bioconversion of waste. Immobilization is defined as confining the molecules or cells to a distinct phase from the substrates, and the products move freely in and out of the phase [12]. Whole-cell immobilization is a simple and effective technique and can be applied for biodegradation [13, 14]. Having known about the keratinase and use of immobilization techniques, the present investigation was carried out using Bacillus sp CBNRBT2 as a whole organism and immobilized cells for the biodegradation of feather waste collected from poultry industry at Kerala, India.

\section{Materials and Methods}

\subsection{Collection of bacteria and subculturing.}

The bacterium Bacillus sp CBNRBT2 was obtained from CNR - Centre for Bioscience and Nanoscience Research, Eachaneri, Coimbatore-21 with NCBI GenBank Accession no: MN243657. This was sub-cultured in nutrient broth, transferred to nutrient agar slant, and stored in $4{ }^{0} \mathrm{C}$ till further use.

\subsection{Optimization of biomass.}

The medium used in this study is as follows: $(\mathrm{g} / 100 \mathrm{~mL})-$ Keratin $-0.1 \mathrm{~g}$, peptone $(0.1 \mathrm{~g})$, glucose $(0.1 \mathrm{~g}), \mathrm{NaCl}(0.02 \mathrm{~g}), \mathrm{K}_{2} \mathrm{HPO}_{4}(0.004 \mathrm{~g})$, yeast extract $(0.05 \mathrm{~g}), \mathrm{MgSO}_{4}(0.02 \mathrm{~g})$, $\mathrm{K}_{2} \mathrm{H}_{2} \mathrm{PO}_{4}(0.05 \mathrm{~g})$. Initial $\mathrm{pH}$ was adjusted to $\mathrm{pH} 7$ with $1 \mathrm{~N} \mathrm{HCl}$, sterilized by autoclaving. The media was allowed to reach room temperature and added $1 \mathrm{ml}$ of culture was added and incubated at $37^{\circ} \mathrm{C}$ for $24 \mathrm{~h}$. Seven $250 \mathrm{~mL}$ conical flasks were taken and inoculated with the organism. Biomass production was done with the above medium for different days, i.e., $1-7$ days. After every day of incubation, the $100 \mathrm{~mL}$ culture was centrifuged at $15000 \mathrm{rpm}$, the supernatant was discarded, the pellet was lyophilized, and the biomass was calculated as follows: Biomass $=$ weight of the tube with dried pellet - empty tube. The same medium was made with different $\mathrm{pH}$ and optimized for $\mathrm{pH}$ for biomass production. Likewise, it was done for different temperatures $\left(25,30,35,40\right.$, and $\left.45^{\circ} \mathrm{C}\right)$.

\subsection{Optimization of biomass with RSM.}

Optimization of physical conditions was carried out using response surface methodology by central composite design. Based on one factor at a time (OFAT) trials, temperature, $\mathrm{pH}$, and incubation time were identified to be significant variables in biomass production. The combination and interaction of the factors needed to increase the production 
of biomass by Bacillus spp were studied by statistical investigation using Design expert version 7.0, Stat-Ease. This process encompasses different empirical methods to assess the association of experimental variables and calculate the significant concentration of dependent and independent factors.

A central composite design was employed to acquire the experimental data that matches in full Quadratic model signifying the response surface over a comparatively broad range of parameters. The range and the levels of experimental variables investigated are presented in Table 1.

The quadratic equation,

$$
\mathrm{Y}=\gamma_{0}+\gamma_{1} \mathrm{~A}+\gamma_{2} \mathrm{~B}+\gamma_{3} \mathrm{C}+\gamma_{4} \mathrm{~A}^{2}+\gamma_{5} \mathrm{~B}^{2}+\gamma_{6} \mathrm{C}^{2}+\gamma_{7} \mathrm{AB}+\gamma_{8} \mathrm{AC}+\gamma_{9} \mathrm{CD}
$$

where $\mathrm{Y}$ is the response, $\mathrm{A}, \mathrm{B}$ and $\mathrm{C}$ are the coded independent input variables, $\gamma_{\mathrm{o}}$ is the intercept term, $\gamma_{1}, \gamma_{2}$, and $\gamma_{3}$ are the coefficients presenting the linear effects, $\gamma_{4}, \gamma_{5}$ and $\gamma_{6}$, are the quadratic coefficients presenting the $\mathrm{R}^{2}$ effects and, $\gamma_{7}, \gamma_{8}$, and $\gamma_{9}$ are a product that has crossed coefficients presenting interaction effect.

Table 1. Design summary (Factors and levels) of RSM-CCD.

\begin{tabular}{c|c|c|c|c|c|c|c|c} 
Factor & Name & Units & \multicolumn{2}{|c|}{ Low } & \multicolumn{2}{c|}{ High } & Mean & Std. Dev. \\
\hline & & & Coded & Actual & Coded & Actual & & \\
\hline $\mathrm{A}$ & $\mathrm{pH}$ & & -1 & 5 & 1 & 9 & 7 & 1.69562 \\
\hline $\mathrm{B}$ & Temperature & $\mathrm{C}$ & -1 & 30 & 1 & 40 & 35 & 4.23905 \\
\hline $\mathrm{C}$ & Incubation time & days & -1 & 2 & 1 & 6 & 4 & 1.69562
\end{tabular}

Table 2. Test of importance for regression coefficient.

\begin{tabular}{c|c|c|c|c|c}
\multirow{2}{*}{ Run } & A:pH & B:Temperature & C:Incubation time & \multicolumn{2}{c}{ Biomass } \\
\cline { 2 - 6 } & & C & Days & Actual & Predicted \\
\hline 1 & 7 & 26.6 & 4 & 8.9 & 9.15 \\
\hline 2 & 5 & 30 & 2 & 17.9 & 2.71 \\
\hline 3 & 7 & 35 & 4 & 18.6 & 18.25 \\
\hline 4 & 7 & 35 & 4 & 7.4 & 7.2 \\
\hline 5 & 10.3 & 35 & 4 & 3.4 & 4.48 \\
\hline 6 & 3.6 & 35 & 4 & 9.1 & 9.3 \\
\hline 7 & 7 & 35 & 7.3 & 10.8 & 10.83 \\
\hline 8 & 9 & 30 & 2 & 18.9 & 18.25 \\
\hline 9 & 7 & 35 & 4 & 7.2 & 7.83 \\
\hline 10 & 7 & 43.4 & 4 & 18.2 & 18.25 \\
\hline 11 & 7 & 35 & 4 & 4.8 & 4.87 \\
\hline 12 & 9 & 40 & 6 & 8.4 & 8.09 \\
\hline 13 & 9 & 40 & 2 & 6.8 & 6.85 \\
\hline 14 & 9 & 30 & 6 & 8.9 & 8.59 \\
\hline 15 & 5 & 30 & 6 & 3.8 & 3.13 \\
\hline 16 & 5 & 40 & 2 & 6.4 & 7.07 \\
\hline 17 & 7 & 35 & 0.63 & 17.8 & 18.25 \\
\hline 18 & 7 & 35 & 4 & 10.4 & 9.75
\end{tabular}

\subsection{Production and characterization of keratinase by Bacillus sp.}

Production of keratinase was done in the following medium: Keratin $-0.1 \mathrm{~g}$, peptone $(0.1 \mathrm{~g})$, glucose $(0.1 \mathrm{~g}), \mathrm{NaCl}(0.02 \mathrm{~g}), \mathrm{K}_{2} \mathrm{HPO}_{4}(0.004 \mathrm{~g})$, yeast extract $(0.05 \mathrm{~g}), \mathrm{MgSO}_{4}(0.02 \mathrm{~g})$, $\mathrm{K}_{2} \mathrm{H}_{2} \mathrm{PO}_{4}(0.05 \mathrm{~g})$. Initial $\mathrm{pH}$ was adjusted to $\mathrm{pH} 7$ with $1 \mathrm{~N} \mathrm{HCl}$. Keratin powder $(20 \mathrm{mg})$ mixed in Tris- $\mathrm{HCl}$ buffer $(100 \mathrm{mM}, \mathrm{pH} 7.8 ; 3.8 \mathrm{ml})$, was incubated with above obtained crude enzymatic extract $(0.2 \mathrm{ml})$ for $1 \mathrm{~h}$ at $37^{\circ} \mathrm{C}$. After incubation, the samples were kept at $4{ }^{\circ} \mathrm{C}$ for $10 \mathrm{~min}$ and then centrifuged for $10 \mathrm{~min}$ at $10,000 \mathrm{rpm}$ at $4^{\circ} \mathrm{C}$. The absorbance of the supernatant at $280 \mathrm{~nm}$ was measured by spectrophotometry against a blank. The unit of enzyme activity was determined as prescribed [15]. Polyacrylamide gel electrophoresis was performed to determine the molecular weight of crude enzyme using $10 \%$ separating gel and stained with 
$0.5 \%$ coomassie brilliant blue in water, acetic acid, methanol (45:10:45). Followed by destaining with water: acetic acid: methanol (45:10:45), and the result was observed using gel documentation, and the molecular weight was identified.

\subsection{Immobilization of Bacillus sp.}

$4 \%$ of sodium alginate was prepared in cell-free extract and sterilized in distilled water in the ratio of 75: 25. The sodium alginate was dissolved by incubating in a water bath at 60 ${ }^{\circ} \mathrm{C}$ for $3 \mathrm{~h}$. The slurry was constantly mixed for $2-10$ min to get a uniform mixture and was added to $2 \%$ of calcium chloride with the help of micropipette drop by drop. The encapsulated sample was incubated for 2 hours and was filtered and dried at room temperature. The dried immobilized sample was stored.

\subsection{Estimation of keratinase activity - whole organism vs. immobilized organism.}

$5 \mathrm{mg}$ of keratin was dissolved with $1 \mathrm{~mL}$ of Tris - HCL buffer (pH 8.0;50mM). $1 \mathrm{~mL}$ of the above suspension was mixed with $1 \mathrm{~mL}$ culture of the whole organism ( $24 \mathrm{~h}$ culture of Bacillus spp) or $1 \mathrm{~mL}$ of alginate beads containing culture in two different conical flasks and kept at $37^{\circ} \mathrm{C}$ for different time intervals of 30, 120, 180, 240, 300, 360 and $420 \mathrm{~min}$. Following the incubation, it was added with $2 \mathrm{~mL}$ Trichloroacetic acid (TCA) $(0.4 \mathrm{M})$. The solution was centrifuged at $5000 \mathrm{rpm}$ for $15 \mathrm{~min}$. The supernatant was read at $595 \mathrm{~nm}$ to determine keratin degradation [16].

\subsection{Comparison of Feather degrading activity - whole organism vs immobilized organism.}

24 h grown Bacillus spp culture and immobilized bacterial culture was mixed separately with a sterilized chicken feather (weight $9.3 \pm 0.2 \mathrm{mg}$ ) in a conical flask with medium concentration, as mentioned in above methods (without keratin). The weight of the degraded feather was measured at a regular time interval, and the percentage of degradation was determined.

\section{Results and Discussion}

\subsection{Optimization of biomass.}

When the organism was allowed to grow in the chosen medium, it was showing maximum growth on the $7^{\text {th }}$ day (Figure 1). Having 7 days as constant, the influence of varied $\mathrm{pH}$ was tried, where $\mathrm{pH} 7$ showed most biomass growth (Figure 2). Effective biomass estimation was observed at the temperature of $37^{\circ} \mathrm{C}$, when compared to other temperatures (Figure 3).

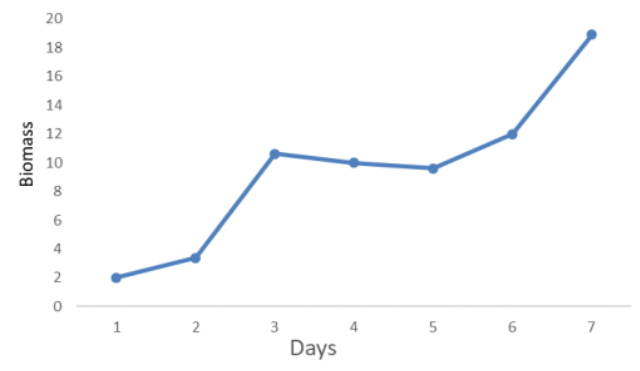

Figure 1. Biomass estimation from different days of incubation. 


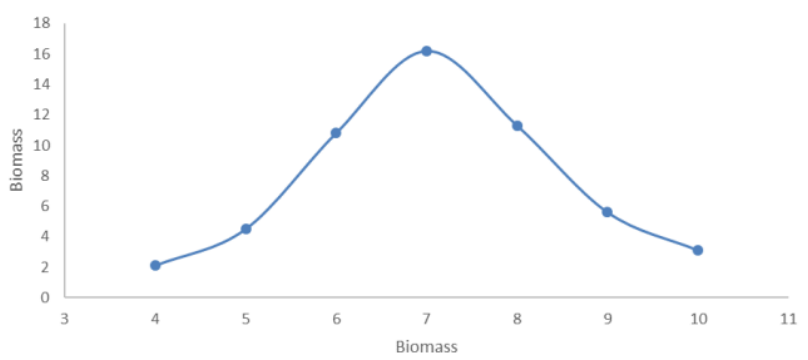

Figure 2. Biomass estimation from various $\mathrm{pH}$.

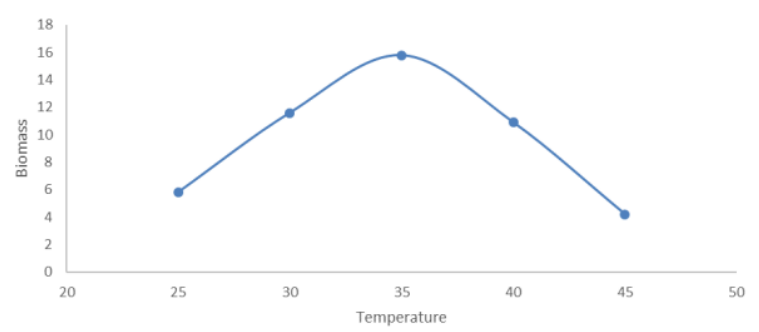

Figure 3. Biomass estimation from various temperature.

Central composite design with trial and predicted results for biomass production was carried out (Table 2). The equation reflects the biomass formation as an empirical operation in terms of coded factors as,

Biomass $=18.249+0.8074 \mathrm{~A}-0.3924 \mathrm{~B}+0.6620 \mathrm{C}-0.7875 \mathrm{AB}-2.4625 \mathrm{AC}+0.1875 \mathrm{BC}-$ $4.3882 \mathrm{~A}^{2}-3.4513 \mathrm{~B}^{2}-3.55744 \mathrm{C}^{2}$

Analysis of variance (ANOVA) for RSM quadratic model provided the F-value 117.1919, with $\mathrm{P}$-values of the model $(\mathrm{P}<0.0001)$, suggesting its significance. The coefficient of variation $(\mathrm{CV}=7.09 \%)$ was evaluated. The goodness of fit was scrutinized by the determination coefficient $\left(\mathrm{R}^{2}=0.9915\right)$ that suggests that a sample difference of more than 99.15\% was ascribed to the variables. The adjusted regression value (Adj $R^{2}=0.9830$ ) was acceptable to approve the importation of the model. The outcome of the formula (quadratic equation) model in the form of ANOVA with the significance of each coefficient and P-values are listed in Table 3.

Table 3. Test of significance for regression coefficient.

\begin{tabular}{|c|c|c|c|c|c|c|}
\hline Source & $\begin{array}{l}\text { Sum of } \\
\text { Squares }\end{array}$ & df & $\begin{array}{l}\text { Mean } \\
\text { Square }\end{array}$ & F Value & $\begin{array}{l}\text { p-value } \\
\text { Prob > F }\end{array}$ & \\
\hline Model & 536.0125 & 9 & 59.55695 & 117.1919 & $<0.0001$ & significant \\
\hline A-pH & 8.903845 & 1 & 8.903845 & 17.52035 & 0.0024 & \\
\hline B-Temperature & 2.102929 & 1 & 2.102929 & 4.137992 & 0.0724 & \\
\hline C-Incubation time & 5.985039 & 1 & 5.985039 & 11.77693 & 0.0075 & \\
\hline $\mathrm{AB}$ & 4.96125 & 1 & 4.96125 & 9.762391 & 0.0122 & \\
\hline $\mathrm{AC}$ & 48.51125 & 1 & 48.51125 & 95.45695 & $<0.0001$ & \\
\hline $\mathrm{BC}$ & 0.28125 & 1 & 0.28125 & 0.553424 & 0.4759 & \\
\hline $\mathrm{A}^{2}$ & 262.8644 & 1 & 262.8644 & 517.2456 & $<0.0001$ & \\
\hline $\mathrm{B}^{2}$ & 162.6018 & 1 & 162.6018 & 319.9562 & $<0.0001$ & \\
\hline $\mathrm{C}^{2}$ & 172.7494 & 1 & 172.7494 & 339.9238 & $<0.0001$ & \\
\hline Residual & 4.573803 & 9 & 0.5082 & & & \\
\hline Lack of Fit & 3.705803 & 5 & 0.741161 & 3.415486 & 0.1288 & not significant \\
\hline Pure Error & 0.868 & 4 & 0.217 & & & \\
\hline Cor Total & 540.5863 & 18 & & & & \\
\hline Std. Dev. & \multicolumn{2}{|l|}{0.712882} & \multicolumn{2}{|l|}{$\mathrm{R}^{2}$} & \multicolumn{2}{|l|}{0.991539} \\
\hline Mean & \multicolumn{2}{|l|}{10.05789} & \multicolumn{2}{|l|}{ Adj R-2 } & \multicolumn{2}{|l|}{0.983078} \\
\hline C.V. $\%$ & \multicolumn{2}{|l|}{7.087782} & \multicolumn{2}{|l|}{ Pred R-2 } & \multicolumn{2}{|l|}{0.945416} \\
\hline Predicted residual error & \multicolumn{2}{|l|}{29.50748} & \multicolumn{2}{|c|}{ Adeq Precision } & \multicolumn{2}{|l|}{30.0412} \\
\hline
\end{tabular}


Three response surfaces were indicated by study of all the probable sequences (Figure 4). These charts show the type of interaction concerning the analyzed factors and hence permit us to acquire the best conditions.

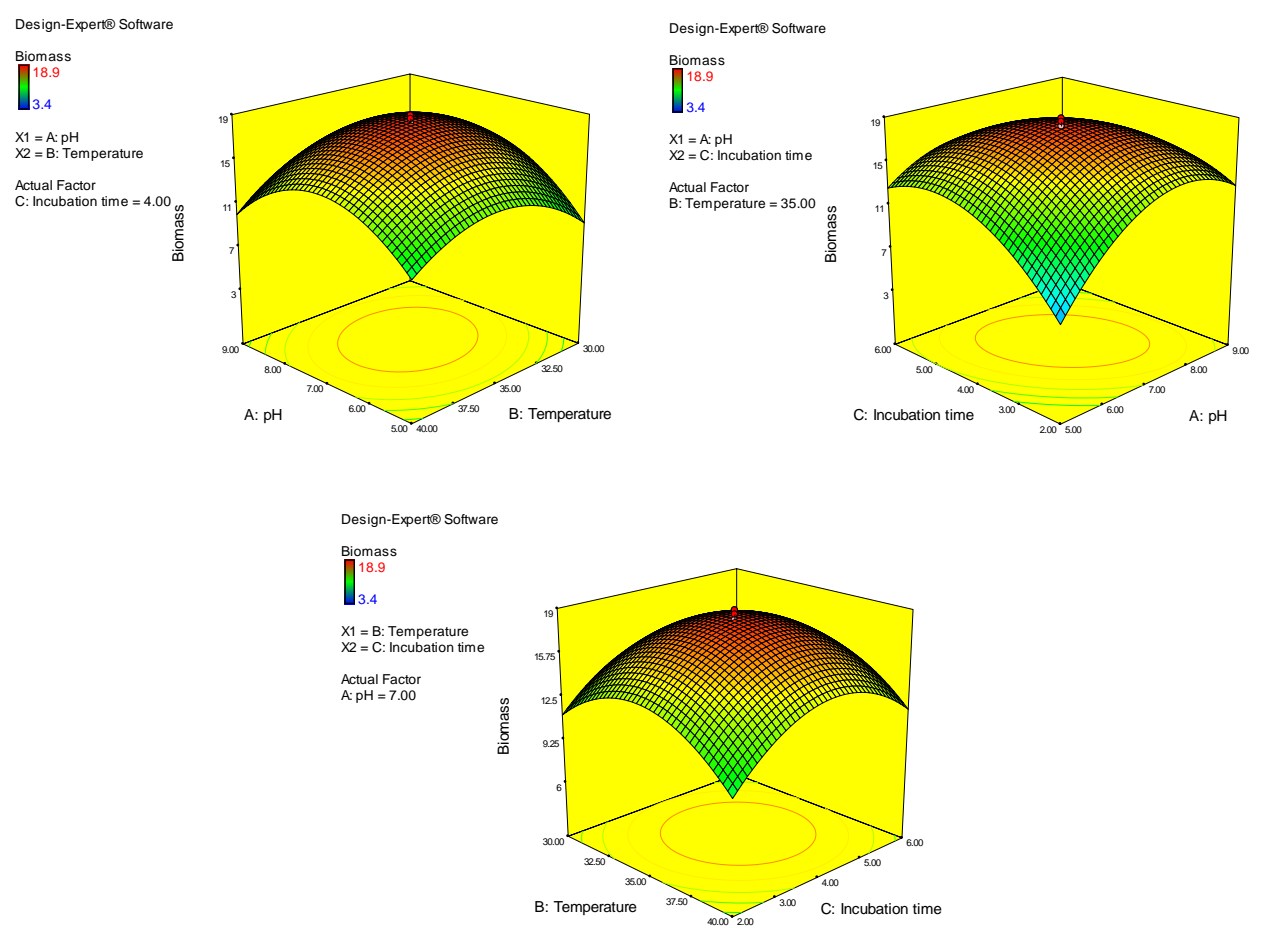

Figure 4. Response Surface Methodology - CCD surface plot with contour plot for different interactions of variables.

\subsection{Production and characterization of keratinase by Bacillus sp.}

The organism was found to produce $30 \mathrm{U} / \mathrm{mL}$ at the prescribed condition. Nagal and Jain (2010) have reported that Bacillus cereus KB043 showed the highest keratinase activity $(39.1 \pm 0.4 \mathrm{UmL}-1)$ where the feather was used as keratin source [17]. They also reported low keratinase values in Bacillus sp. KB037 and KB087 which was ranging from 16.95 \pm 0.4 to $18.05 \pm 0.1 \mathrm{UmL}-1$. In this study, Bacillus spp was found to produce keratinase of $64 \mathrm{KDa}$ (Figure 5). Tiwary and Gupta [18] reported $58 \mathrm{KDa}$ sized dimeric keratinase in Bacillus licheniformis ER-15.

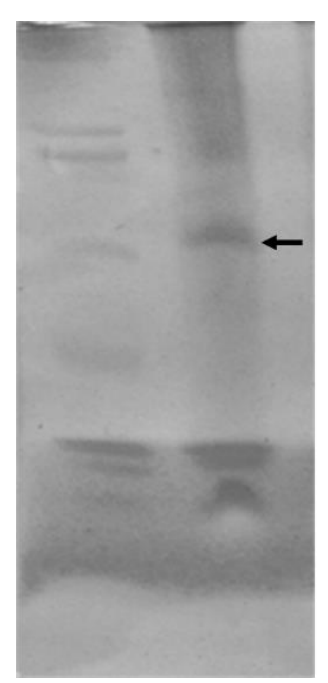

Figure 5. SDS-PAGE: Line 1. Marker, Line 2. Sample 64 KDa. 
3.3. Estimation of keratinase activity - whole organism vs. immobilized organism.

It is evidenced that the immobilized organisms produced more activity than the whole organism, where the whole organism needs to divide more. Thus, there was reduced activity until 420 min (Figure 6). There are reports stating that Bacillus sp to have high keratinase activity $[17,19,20]$.

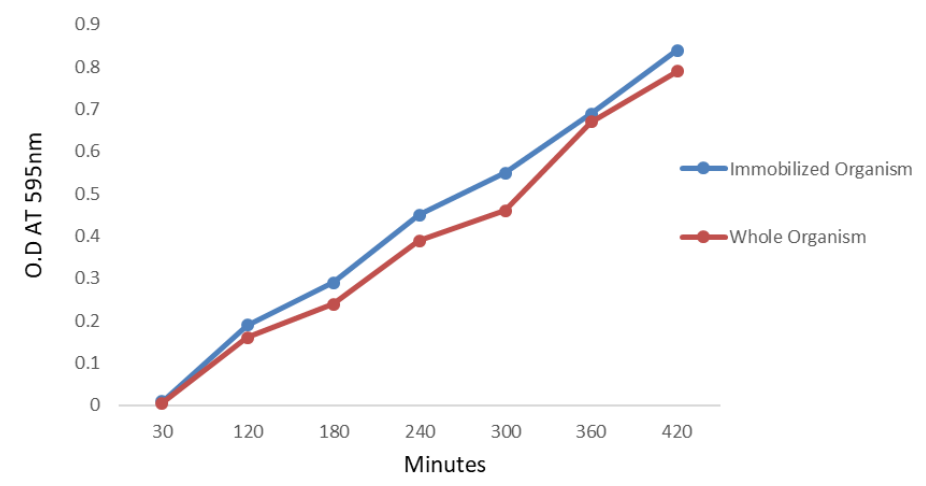

Figure 6. Keratinase assay of Immobilized Organism and Whole Organism.

\subsection{Comparison of Feather degrading activity - whole organism vs immobilized organism.}

The immobilized organism was degrading about $41 \%$ of a feather in 14 days, where it was $38 \%$ by the whole organism (Figure 7). Thus, it was obvious that immobilized organism is good in degrading the feather. Supporting our view, Prakash et al. [20] also used whole immobilized cells of Bacillus halodurans strain PPKS-2 for effective continuous degradation of a feather, and even they found immobilized cells are better than the whole cells alone. Dhiva et al. [21] used Pseudomonas aeruginosa SU1 to produce keratinolytic enzymes, which was used for feather degradation. Abirami et al. [22] used keratinolytic organisms to degrade cattle hooves. Thus, microbial products are known to be used for various applications [21-23].

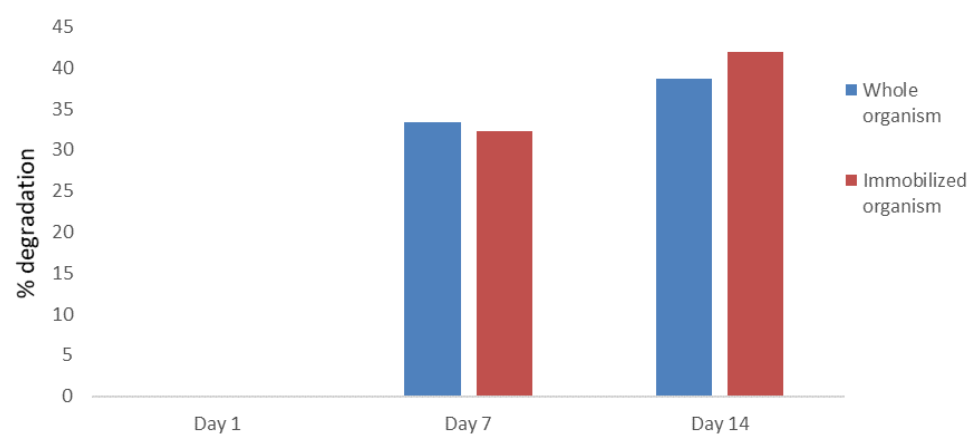

Figure 7. Efficiency of the immobilized and whole organism in feather degradation.

\section{Conclusions}

In this study, Bacillus sp CBNRBT2 was optimized for biomass production, where the optimal condition was found as 7 days incubation, $\mathrm{pH} 7$, and $35^{\circ} \mathrm{C}$ temperature. RSM was used to find the best condition, and the organism was produced in the obtained condition. The produced biomass was used to immobilize the whole cell in alginate. Simultaneously, the organism was checked for its keratinase production ability and characterization of keratinase. The organism was producing $30 \mathrm{U} / \mathrm{mL}$ of keratinase, and the molecular weight was found to 
be $64 \mathrm{KDa}$. The immobilized cell was checked for its ability to produce keratinase and feather degradation. The immobilized cells were found to be efficient than the whole cells. Therefore, this approach can be used for treating poultry waste.

\section{Funding}

This research received no external funding.

\section{Acknowledgments}

All the authors acknowledge the Centre for Bioscience and Nanoscience Research, Eachaneri, Coimbatore-21, for having given the bacterial sample used in this study.

\section{Conflicts of Interest}

The authors declare no conflict of interest.

\section{References}

1. Peng, Z.; Mao, X.; Zhang, J.; Du, G.; Chen, J. Effective biodegradation of chicken feather waste by cocultivation of keratinase producing strains. Microbial cell factories 2019, 18, 1-11, https://doi.org/10.1186/s12934-019-1134-9.

2. Tamreihao, K.; Mukherjee, S.; Khunjamayum, R.; Devi, L.J.; Asem, R.S.; Ningthoujam, D.S. Feather degradation by keratinolytic bacteria and biofertilizing potential for sustainable agricultural production. Journal of basic microbiology 2019, 59, 4-13, https://doi.org/10.1002/jobm.201800434.

3. Miskiewicz, A.; Kowalczyk, P.; Oraibi, S.M.; Cybulska, K.; Misiewicz, A. Bird feathers as potential sources of pathogenic microorganisms: a new look at old diseases. Antonie van Leeuwenhoek 2018, 111, 1493-1507, https://doi.org/10.1007/s10482-018-1048-2.

4. Choudary, R.B.; Nehanth, R. Effects of fibre content on mechanical properties of chicken feather fibre/PP composites. Materials Today: Proceedings 2019, 18, 303-309, https://doi.org/10.1016/j.matpr.2019.06.305.

5. Yong, B.; Fei, X.; Shao, H.; Xu, P.; Hu, Y.; Ni, W.; Xiao, Q.; Tao, X.; He, X.; Feng, H. Recombinant expression and biochemical characterization of a novel keratinase BsKER71 from feather degrading bacterium Bacillus subtilis S1-4. AMB Express 2020, 10, 1-10, https://doi.org/10.1186/s13568-019-0939-6.

6. Tamreihao, K.; Mukherjee, S.; Khunjamayum, R.; Devi, L.J.; Asem, R.S.; Ningthoujam, D.S. Feather degradation by keratinolytic bacteria and biofertilizing potential for sustainable agricultural production. Journal of basic microbiology 2019, 59, 4-13, https://doi.org/10.1002/jobm.201800434.

7. Ningthoujam, D.S., Tamreihao, K., Mukherjee, S., Khunjamayum, R., Devi, L.J.; Asem, R.S. Keratinaceous Wastes and Their Valorization through Keratinolytic Microorganisms. In: Keratin. IntechOpen. 2018; http://dx.doi.org/10.5772/intechopen.80051.

8. Arokiyaraj, S.; Varghese, R.; Ahmed, B.A.; Duraipandiyan, V.; Al-Dhabi, N.A. Optimizing the fermentation conditions and enhanced production of keratinase from Bacillus cereus isolated from halophilic environment. Saudi Journal of Biological Sciences 2019, 26, 378-381, https://doi.org/10.1016/j.sjbs.2018.10.011.

9. Li, Q. Progress in microbial degradation of feather waste. Frontiers in Microbiology 2019, 10, 2717, https://doi.org/10.3389/fmicb.2019.02717.

10. Srivastava, B.; Khatri, M.; Singh, G.; Arya, S.K. Microbial keratinases: An overview of biochemical characterization and its eco-friendly approach for industrial applications. Journal of Cleaner Production 2020, 252, https://doi.org/10.1016/j.jclepro.2019.119847.

11. Hassan, M.A.; Abol-Fotouh, D.; Omer, A.M.; Tamer, T.M.; Abbas, E. Comprehensive insights into microbial keratinases and their implication in various biotechnological and industrial sectors: A review. International Journal of Biological Macromolecules 2020, 154, 567-583, https://doi.org/10.1016/j.ijbiomac.2020.03.116.

12. Nguyen, H.H.; Lee, S.H.; Lee, U.J.; Fermin, C.D.; Kim, M. Immobilized enzymes in biosensor applications. Materials 2019, 12, 121, https://doi.org/10.3390/ma12010121.

13. Partovinia, A.; Rasekh, B. Review of the immobilized microbial cell systems for bioremediation of petroleum hydrocarbons polluted environments. Critical Reviews in Environmental Science and Technology 2018, 48, 1-38, https://doi.org/10.1080/10643389.2018.1439652.

14. Fareed, A.; Riaz, S.; Nawaz, I.; Iqbal, M.; Ahmed, R.; Hussain, J.; Hussain, A.; Rashid, A.; Naqvi, T.A. Immobilized cells of a novel bacterium increased the degradation of N-methylated carbamates under low temperature conditions. Heliyon 2019, 5, e02740, https://doi.org/10.1016/j.heliyon.2019.e02740. 
15. Mazotto, A.M.; Couri, S.; Damaso, M.; Vermelho, A.B. Degradation of feather waste by Aspergillus niger keratinases: Comparison of submerged and solid-state fermentation. International Biodeterioration \& Biodegradation. 2013, 85, 189-195, https://doi.org/10.1016/j.ibiod.2013.07.003.

16. Navone, L.; Speight, R. Understanding the dynamics of keratin weakening and hydrolysis by proteases. PLoS ONE 2018, 13, e0202608, https://doi.org/10.1371/journal.pone.0202608.

17. Nagal, S.; Jain, P.C. Feather degradation by strains of bacillus isolated from decomposing feathers. Brazilian Journal of Microbiology 2010, 41, 196-200, https://doi.org/10.1590/s1517-83822010000100028.

18. Tiwary, E.; Gupta, R. Medium optimization for a novel $58 \mathrm{kDa}$ dimeric keratinase from Bacillus licheniformis ER-15: Biochemical characterization and application in feather degradation and dehairing of hides. Bioresource Technology 2010, 101, 6103-6110, https://doi.org/10.1016/j.biortech.2010.02.090.

19. Suntornsuk, W.; Suntornsuk, L. Feather degradation by Bacillus sp. FK 46 in submerged cultivation. Bioresource Technology 2003, 86, 239-243, https://doi.org/10.1016/s0960-8524(02)00177-3.

20. Prakash, P., Jayalakshmi, S.K., Sreeramulu, K. Production of keratinase by free and immobilized cells of Bacillus halodurans strain PPKS-2: partial characterization and its application in feather degradation and dehairing of the goat skin. Applied Biochemistry and Biotechnology 2010, 160, 1909-20, https://doi.org/10.1007/s12010-009-8702-0.

21. Dhiva, S.; Ranjith, K. R.; Prajisya P, Sona K P, Narendrakumar G, Prakash P, Emilin Renitta R, Antony V Samrot. Optimization of keratinase production using Pseudomonas aeruginosa SU-1 having feather as substrate. Biointerface Research in Applied Chemistry 2020, 10, 6540-6549, https://doi.org/10.33263/BRIAC105.65406549.

22. Abirami, S.; Ragavi, R.; Samrot, A.V. Utilization of Keratinolytic Lichtheimia corymbifera AS1 for Degradation of Cattle Hoove - a Slaughter House Waste to Use in Plant Growth. Biointerface Research in Applied Chemistry 2020, 10, 6417-6426, https://doi.org/10.33263/BRIAC105.64176426.

23. Paulraj, P.; Fung, H.Z; Gunaseelan, R.; Samrot, A.V.; Ismail, A.A.; Iyappan, P.; Chandramohan, M.; Purayil, S.K.; Sajeesh, P,; Ketharin, T.; Javad, P.T.M.; Selvarani, A.J. Isolation and characterization of phosphate solubilizing bacteria from agricultural soils for a potential use in cultivating Capsicum frutescens. Biointerface Research in Applied Chemistry 2020, 10, 2020, 5161-5173, https://doi.org/10.33263/BRIAC102.161173. 